\title{
Analysis of Power and Aerobic Capacity in Elite Athletes of Both Genres, Practitioners of Different Sports
}

\author{
Ricardo Cesar Alves Ferreira ${ }^{{ }^{*}}$, Fabiano de Barros Souza ${ }^{1,2}$, Wellington Ribeiro', \\ Wendel Simões Fernandes ${ }^{1}$, Alessandra de Almeida Fagundes ${ }^{1}$, \\ Leandro Yukio Alves Kawaguchi ${ }^{1}$, Carolina S. Carvalho', Rodrigo Alexis Lazo-Osorio' \\ ${ }^{1}$ IP\&D-Lab. Physiology \& Pharmacodynamic, University of Vale do Paraíba (Univap), São José dos Campos, \\ Brazil \\ ${ }^{2}$ FEA (Faculty of Education \& Arts), Physical Education, University of Vale do Paraiba (Univap), São José dos \\ Campos, Brazil \\ Email: ricardocalves@hotmail.com
}

Received 18 September 2014; revised 6 October 2014; accepted 14 October 2014

Academic Editor: Sardar Mohammadi, University of Kurdistan, Iran

Copyright (C) 2014 by authors and Scientific Research Publishing Inc. This work is licensed under the Creative Commons Attribution International License (CC BY). http://creativecommons.org/licenses/by/4.0/

(c) (i) Open Access

\section{Abstract}

Oxygen uptake $\left(\mathrm{VO}_{2}\right.$ peak) has been very important in functional assessment of cardiorespiratory fitness. The Ergospirometry is a noninvasive procedure used to evaluate physical performance or ability of an individual, through the analysis of the gases with the respiratory variables. In sports, this method of evaluation is crucial, because it brings a significant contribution to the verification of aerobic fitness, such as, the maximal oxygen uptake ( $\mathrm{VO}_{2}$ max.), and anaerobic threshold. The present study aims to evaluate the power and aerobic capacity in professional and under-20 soccer players, handball athletes, and women footballers, using the technique of gas analysis. For the study, 48 athletes, who participated voluntarily, were divided into 4 groups of 12 athletes. The $\mathrm{VO}_{2}$ peak, the average speed and heart rate at anaerobic threshold, as well as respiratory exchange ratio were analyzed. We found that the values were always greater for the group of professional football players, with the exception of the average consumption of maximum $\mathrm{O}_{2}$, where the difference of the footballers in the under-20 category was not significant. Additional values that were analyzed indicated that there were some physical similarities between the other groups that should be noted. The respiratory exchange ratio was significantly lower for the group of women footballers. Based on this data, it was concluded that the specificity of sport as dimensions of the pitch, duration, and tactical system, morphology and sex of the athlete, directly influences the values of the $\mathrm{VO}_{2}$ peak, lactate threshold and respiratory exchange ratio for athletes of different

\footnotetext{
"Corresponding author.
} 
sports at the same stage of periodization of fitness.

\title{
Keywords
}

\author{
Ergospirometry, Soccer, Female Soccer, Handball, $\mathrm{VO}_{2}$
}

\section{Introduction}

The maximum oxygen uptake $\left(\mathrm{VO}_{2}\right.$ max.) can be defined as the maximum volume of oxygen per unit time that an individual captures, breathing a gas mixture of atmospheric air during exercise. It is achieved when reaching maximum values of cardiac output and peripheral oxygen extraction and is not exceeded even with increase in load of muscle work (Leal, Souza, Martins, Magini, \& Martins, 2006; Grieco, Cortes, Greska, Lucci, \& Onate, 2011; Dittrich, Da Silva, Castagna, De Lucas, \& Guglielmo, 2011). The $\mathrm{VO}_{2}$ max. is the highest value of consumption achieved during the exercise test; this has been considered an important parameter as a predictor of performance, because the human capacity to perform exercises of long and medium term depends primarily on the aerobic metabolism and thus, an index is used to rank very cardiorespiratory functional capacity, especially in athletes (Basset \& Howley, 2000; Leal, Souza, Magini, \& Martins, 2006; Grieco, Cortes, Greska, Lucci, \& Onate, 2011; Dittrich, Da Silva, Castagna, De Lucas, \& Guglielmo, 2011). The maximum oxygen consumption has long been the most important and most used means of physiological indicator for the assessment of aerobic fitness, but some studies have demonstrated that this index is not sufficiently able to discriminate performance in aerobic events (Da Silva, Dittrich, \& Guglielmo, 2011). And the constant search for better methods of training and reliable means of assessing the aerobic fitness becomes relevant (Leal, Souza, Magini, \& Martins, 2006; Nicolao, Pedrinelli, Zogaib, Orbetelli, \& Neto, 2010). The anaerobic threshold is the point where the transition from aerobic to anaerobic occurs and is also an index that adequately reflects the physical fitness, being used in clinical practice in the evaluation and training of athletes (Leal, Souza, Magini, \& Martins, 2006; Da Silva, Dittrich, \& Guglielmo, 2011). When characterized exclusively from the gas exchange, anaerobic threshold to receive the designation of "ventilatory threshold" can be defined as the exercise intensity above which lactic acid production exceeds its removal, and hyperventilation as a consequence (Barros \& Guerra, 2004; Almeida, 2009).

The Ergospirometry, a noninvasive and useful procedure in the evaluation of physical performance or functional capacity of an individual reconciles the analysis of the inspired gases, oximetry and respiratory variables (Tillaar \& Cabri, 2012; Da Silva, Castagna, Carminatti, Foza, Guglielmo, \& De Oliveira, 2010). This method is able to determine predictive factors linked to performance indicators, such as exercising intolerance and identifying metabolic transition beyond facilitate the prescription of exercise intensity (Leal, Souza, Martins, Magini, \& Martins, 2006; Grieco, Cortes, Greska, Lucci, \& Onate, 2011; Dittrich, Da Silva, Castagna, De Lucas, \& Guglielmo, 2011).

The football (soccer) is characterized by frequent changes of intensity, short breaks recovery, sudden stops and changes of direction, i.e., athletes experience intermittent nature of efforts during training and competitions. Despite these characteristics, the production of energy used by the players is coming mainly from aerobic metabolism, which is related to the athlete's ability to maintain the intensity of effort during the game by means of recovery between high-intensity stimuli (Da Silva, Dittrich, \& Guglielmo, 2011).

The handball is a sport that requires a high level of general and specific conditioning, the effective time of a match comprises 40 minutes, with consecutive attacks and defenses played at high intensity and different components such as acceleration, change of direction and jumps, diversity effort requires a thorough preparation in terms of strength, speed and strength (Boraczyński \& Urniaż, 2008).

\section{Methodology}

48 athletes were divided into 4 groups of 12 athletes. The first group consists of 12 young people who act as soccer players in the under-20 (FMJ), with a mean age of $17( \pm 0.5)$ years and mean weight of $67.8( \pm 4.5) \mathrm{kg}$. The second group consisted of 12 professional soccer players (FMP), with a mean age of $23( \pm 1.6)$ years and mean weight of $73.1( \pm 4.7) \mathrm{kg}$, the third group was formed by players female $(\mathrm{FF})$, the mean age was $21( \pm 1.3)$ 
and mean weight of $57.6( \pm 3.1) \mathrm{kg}$, and finally the fourth group consisted of handball athletes (HM) aged average of $19( \pm 1.3)$ and average weight of $83.8( \pm 7) \mathrm{kg}$. The study was approved by the University of Vale do Paraíba-UNIVAP Ethics Committee (CEP). Subjects were informed of this study and was applied consent.

Micromed a digital electrocardiograph for recording and analysis of electrocardiogram (ECG) during stress was used for the study; a treadmill brand Inbrasport, Super ATL; VO2000 analyzer gases MedGraphics brand, coupled to a microcomputer equipped with the Elite software produced by Micromed; nose clip; disposable electrodes; disposable razors; disposable sandpaper; alcohol 70.

The tests were performed in the pre-season, more precisely in the pre-competition period of four groups of athletes studied in laboratory of evaluation-LAEF, Faculty of Health Sciences, University of Vale do Paraíba -UNIVAP. The tests took place in a controlled environment with an ambient temperature of $24^{\circ} \mathrm{C}$, and relative humidity of $60 \%$ air environment. The evaluation protocol used was progressive effort with constant slope of $2 \%$ and initial velocity of $4.0 \mathrm{~km} / \mathrm{h}$. An increment in velocity of $1.0 \mathrm{~km} / \mathrm{h}$ every minute test until the fourth minute; after the fourth minute the speed increment was also $1.0 \mathrm{~km} / \mathrm{h}$, but occurring every two minutes test. The duration of the tests was determined by the athlete's exhaust, which when reached signaled to the evaluator, who then started with the initial recovery phase velocity of $5.0 \mathrm{~km} / \mathrm{h}$, with a decrement of $1.0 \mathrm{~km} / \mathrm{h}$ after the first minute continued until the end of recovery, determined by the stabilization of the heart rate of the athlete.

For statistical analysis, the test of variance one-way ANOVA, considering a significance level of $5 \%$ ( $p<$ $0.05)$ was used.

\section{Results}

The results obtained with physiological assessments by four (4) groups were separated and analyzed by means of the table and graphs for a more detailed comparison. Below are listed the values of means and standard deviations (SD) of the groups assessed.

Table 1 shows the mean and SD of anthropometric values (weight and age) and analyzed parameters $\left(\mathrm{VO}_{2}\right.$ and VE) for different athletes. The first group consisted of 12 young people who acted as soccer players in the under-20 category (FMJ), with a mean age of $17( \pm 0.5)$ years, and mean weight of $67.8( \pm 4.5) \mathrm{kg}$. The second group (FMP) was made up of 12 professional soccer players with a mean age of $23( \pm 1.6)$ years, and mean weight of $73.1( \pm 4.7) \mathrm{kg}$. The third group consisted of female soccer players (FF), with a mean age was $21( \pm 1.3)$ and mean weight of $57.6( \pm 3.1) \mathrm{kg}$. Finally, the fourth group (HM) consisted of handball players with a mean age of $19( \pm 1.3)$ and average weight of $83.8( \pm 7) \mathrm{kg}$.

In Figure 1, we can see as a parameter the $\mathrm{VO}_{2}$ peak graphic expressed in $(\mathrm{ml} / \mathrm{kg} \cdot \mathrm{min})$ in different sports, but its important to mention that allow them are in a same condition, all of them was in a pre-season. It means that there are no physical condition advantages between the groups. The understanding and correct interpretation of these parameters may assist coaches in their respective modalities to improve their methods, fitness and tactical practices, the function in the game can be adjust with their ability, enabling better results and performance and helping prevent injuries (Robbins, Goodale, Kuzmits, \& Adams, 2013).

In Figure 2, The Lactate threshold speed $(\mathrm{km} / \mathrm{h})$ is used as parameter to compare an aerobic performance between the groups. In professional soccer players group (FMP) the running speed is higher than athletes from others sports (FF and HM) even when compared with young soccer players (FMJ). However the young soccer players have higher values comparing to handball and female soccer, this parameter is very useful for physical coaches.

Generally the total time of training session corresponds to the same amount of the official game, where pro-

Table 1. Mean and SD of anthropometric values and analyzed parameters.

\begin{tabular}{|c|c|c|c|c|c|c|}
\hline Group & Age & Weight (kg) & VE (l/min) & $\begin{array}{c}\mathrm{VO}_{2} \text { peak } \\
(\mathrm{ml} / \mathrm{kg} \cdot \mathrm{min})\end{array}$ & $\begin{array}{l}\text { Lactate threshold } \\
\qquad(\mathrm{km} / \mathrm{h})\end{array}$ & $\begin{array}{l}\text { Lactate HR } \\
\text { (bpm) }\end{array}$ \\
\hline FMJ & $17.7 \pm 0.58$ & $67.82 \pm 4.54$ & $96.83 \pm 6.86$ & $56.48 \pm 3.08$ & $13.64 \pm 0.45$ & $159.17 \pm 3.66$ \\
\hline FMP & $23.25 \pm 1.66$ & $73.15 \pm 4.72$ & $111.59 \pm 12.64$ & $58.15 \pm 4.48$ & $14.24 \pm 0.37$ & $163.42 \pm 4.21$ \\
\hline $\mathrm{FF}$ & $21.7 \pm 1.34$ & $57.67 \pm 3.14$ & $85.89 \pm 4.21$ & $46.04 \pm 2.90$ & $13.18 \pm 0.59$ & $156.17 \pm 2.76$ \\
\hline HM & $19.00 \pm 1.28$ & $83.83 \pm 7.02$ & $98.79 \pm 10.24$ & $51.70 \pm 3.42$ & $13.30 \pm 0.34$ & $157.91 \pm 3.51$ \\
\hline
\end{tabular}




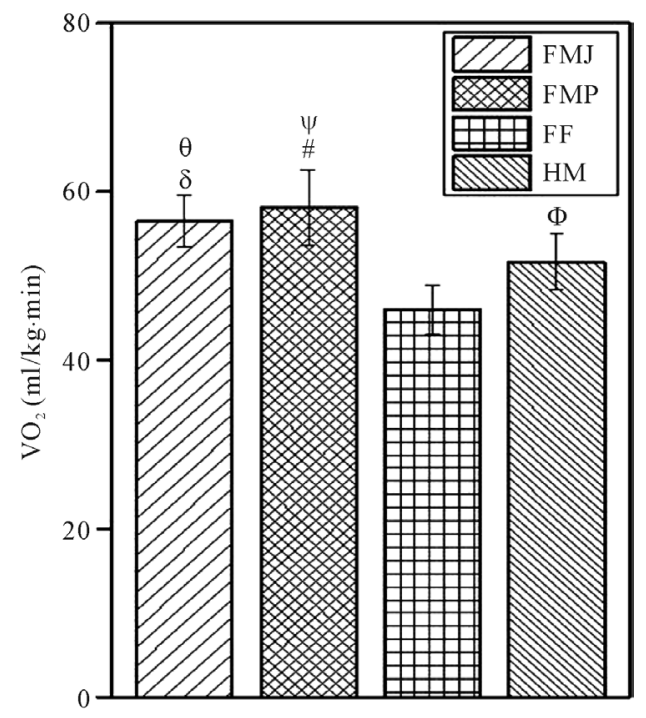

Figure 1. $\mathrm{VO}_{2}$ peak athletes in different sports. FMP versus FF $\mathrm{p}=0.000$ (\#); FMP versus $\mathrm{HM}$ $p=2.92 \mathrm{E}-4(\psi)$; FMJ versus $\mathrm{FF}=0.000 p(\theta)$; FMJ versus HM $p=0.009(\delta)$; HM FF versus $p$ $=0.001(\Phi)$.

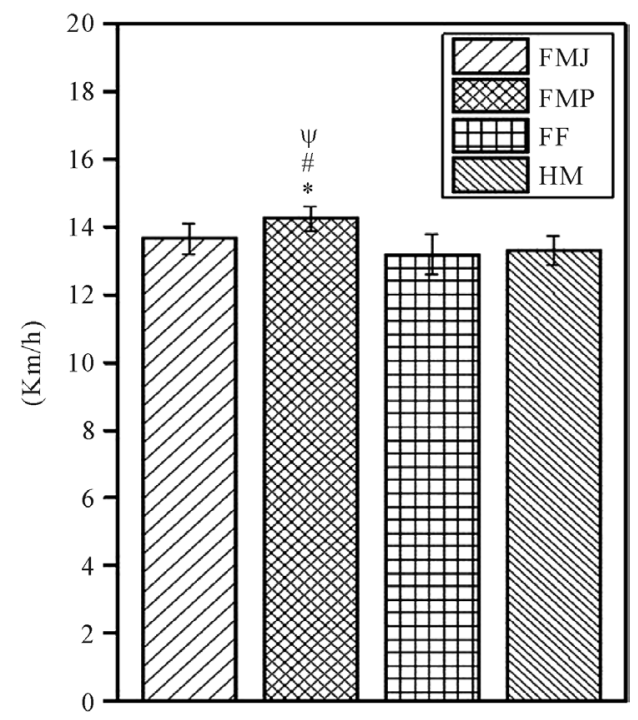

Figure 2. Lactate Threshold, running speed in different sports. FMP versus FMJ $p=0.013(*)$; FMP versus FF $p=7.71 \mathrm{E}-6$ (\#); FMP versus $\mathrm{HM} p=5.88 \mathrm{E}-5(\psi)$.

fessional soccer game are longer than the others sports. In other words the professional soccer players tend to practice during more time; it makes a volume rise, improving their endurance.

Another important way to compare the differences between the different sports is using a heart rate HR anaerobic threshold date, during the test the group FMP who is composed by professional soccer players had a response of HR higher when compared with another groups of athletes, in other words they could keep running even when in a high values of HR and higher intensity, the others groups was not able to support that conditions and interrupted the test before that values. The lactate threshold (LT) is an important method to improve high intensity performance in endurance sports, and it is widely used as an indicator of aerobic fitness in athletes (Figure 3). 


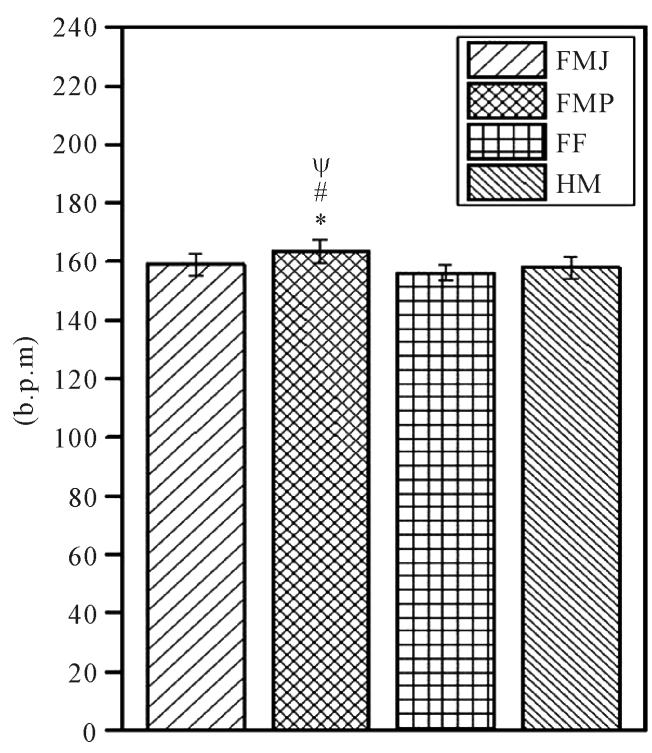

Figure 3. FC anaerobic threshold athletes in different sports. FMP versus FMJ $p=0.026(*)$; FMP FF versus $p=5.15 \mathrm{E}-5(\#)$; FMP versus $\operatorname{HM} p=0.002(\psi)$.

\section{Discussion}

The FMP group showed significant results in $\mathrm{VO}_{2}$ peak when compared to results from the same physiological parameters obtained in groups $\mathrm{FF}$ and $\mathrm{H}$. However, when compared the $\mathrm{FMP} \mathrm{VO}_{2}$ and $\mathrm{VO}_{2}$ of FMJ, there are no significant difference in their results. This has been discussed in several researchs such as Grieco, Cortes, Greska, Lucci, \& Onate (2011); Dittrich, Da Silva, Castagna, De Lucas, \& Guglielmo (2011), who studied the performance of athletes and footballers showed morphological similarity in physical composition of players, having the muscle mass as the main factor of balance between the two categories, as analyzed in this study. The methodology employed in the technical and physical training in the form of football resembles in both categories with regard to intensity and training volume (Kelly, Burnett, \& Newton, 2008).

Still on the $\mathrm{VO}_{2}$ peak groups $\mathrm{FF}$ and $\mathrm{H}$ had significantly lower values for the groups of soccer (FMP and FMJ). The result should be related to factors such as the difference in lean body mass (free fat body massin female athletes). In relation to the handball, researchers like Da Silva, Castagna, Carminatti, Foza, Guglielmo, \& De Oliveira, 2010 in their studies shows the occurrence of physical adaptations of different values caused by the specificity of the spaces where they develop practices and games. Modalities practiced in larger environments allow better conditions of aerobic power (Grieco, Cortes, Greska, Lucci, \& Onate, 2011; Dittrich, Da Silva, Castagna, De Lucas, \& Guglielmo, 2011; Cunha, Lorenzi, Sapata, Lopes, Gaya, \& Oliveira, 2011; Tillaar \& Cabri, 2012).

As in aerobic power, the values in speed $(\mathrm{km} / \mathrm{h})$ and heart rate (bpm) of the anaerobic threshold, FMP group were significantly higher than the other groups, except the HR threshold for FF. There was no significant difference between both groups compared.

These results may be related not only to the environment where the sport is practiced, but also as a consequence of a good aerobic power, which directly influences the values obtained in aerobic capacity (Grieco, Cortes, Greska, Lucci, \& Onate, 2011; Dittrich, Da Silva, Castagna, De Lucas, \& Guglielmo, 2011).

Another consideration to be made is the muscular efficiency, because professional soccer players have training methodology very similar to the category of junior footballers, however, the results obtained, it can be considered more efficient muscles required of professional soccer players corroborating with the following authors (Da Silva, Castagna, Carminatti, Foza, Guglielmo, \& De Oliveira, 2010).

About ventilation, the FMP group also has higher mean value compared to the others. The female group has lower average value in relation to other groups, which is connected to the morphological difference between women, especially with regard to the respiratory system and its capabilities. 


\section{Conclusion}

The results showed that the specificity of the environment where they practice, and training characteristics of the evaluated methods, interfere directly in values of power and aerobic capacity in high yield.

\section{References}

Almeida, A. G. (2009). Avaliação da capacidade anaeróbia de jogadores de futebol através de teste máximo de corrida de Vai-e-Vem. Revista Brasileira de Cineantropometria e Desempenho Humano, 11, 88-93.

Barros, T. L., \& Guerra, I. (2004). Ciência do Futebol (6th ed). São Paulo: Editora Manole.

Basset, D. R., \& Howley, E. T. (2000). Limiting Factors for Maximum Oxygen Uptake and Determinants of Endurance Performance. Medicine \& Science in Sports \& Exercise, 32, 70-84. http://dx.doi.org/10.1097/00005768-200001000-00012

Boraczyński, T., \& Urniaż, J. (2008). Changes in Aerobic and Anaerobic Power Indices in Elite Handball Players Following a 4-Week General Fitness Mesocycle. Journal of Human Kinetics, 19, 131-140. http://dx.doi.org/10.2478/v10078-008-0010-1

Buchheit, M. A., Lepretre, P. M., Behaegel, A. L., Millet, G. P., Cuvelier, G., \& Ahmaid, S. (2009). Cardiorespiratory Responses during Running and Sport-Specific Exercises in Handball Players. Journal of Science and Medicine in Sport, 12, 399-405. http://dx.doi.org/10.1016/j.jsams.2007.11.007

Cunha, G., Lorenzi, T., Sapata, K., Lopes, A. L., Gaya, A. C., \& Oliveira, A. (2011). Effect of Biological Maturation on Maximal Oxygen Uptake and Ventilatory Thresholds Insoccer Players: An Allometric Approach. Journal of Sports Sciences, 29, 1029-1039. http://dx.doi.org/10.1080/02640414.2011.570775

Da Silva, J. F., Castagna, C., Carminatti, L. J., Foza, V., Guglielmo, L. G., \& De Oliveira, F. R. (2010). Physiological Demands of Team-Handball Referees during Games. Journal of Strength and Conditioning Research/National Strength \& Conditioning Association, 24, 1960-1962. http://dx.doi.org/10.1519/JSC.0b013e3181ddb019

Da Silva, J. F., Dittrich, N., \& Guglielmo, L. G. A. (2011). Avaliação aeróbia no futebol. Revista Brasileira de Cineantropometria e Desempenho Humano, 13, 384-391.

Dittrich, N., da Silva, J. F., Castagna, C., de Lucas, R. D., \& Guglielmo, L. G. (2011). Validity of Carminatti’s Test to Determine Physiological Indices of Aerobic Power and Capacity in Soccer and Futsal Players. Journal of Strength and Conditioning Research, 25, 3099-3106. http://dx.doi.org/10.1519/JSC.0b013e3182132ce7

Grieco, C., Cortes, N., Greska, E., Lucci, S., \& Onate, J. (2011). Effects of a Combined Resistance/Plyometric Training Program on Muscular Strength, Running Economy and $\mathrm{VO}_{2}$ Peak in Division I Female Soccer Players. Journal of Strength and Conditioning Research, 6, 1714-1722.

Kelly, C. M., Burnett, A. F., \& Newton, M. J. (2008). The Effect of Strength Training on Three-Kilometer Performance in Recreational Women Endurance Runners. Journal of Strength \& Conditioning, 22, 396-403. http://dx.doi.org/10.1519/JSC.0b013e318163534a

Leal, J. R. E. C. P., Souza, F. B., Magini, M., \& Martins, R. A. B. L. (2006). Estudo comparativo do consumo de oxigênio e limiar anaeróbio em um teste de esforço progressivo entre atletas profissionais de futebol e futsal. Revista Brasileira de Medicina do Esporte, 12, 24-28.

Nicolao, A. L. A., Pedrinelli, A., Zogaib, P. S. M., Orbetelli, R., \& Neto, T. L. B. (2010). Influência da Maturação Sexual no Limiar de Lactato em Jogadoras de Futebol. Revista Brasileira de Medicina do Esporte, 16, 32-36. http://dx.doi.org/10.1590/S1517-86922010000500003

Robbins, D. W., Goodale, T. L., Kuzmits, F. E., \& Adams A. J. (2013). Changes in the Athletic Profile of Elitecollege American Football Players. Journal of Strength \& Conditioning Research, 27, 916-923.

Tillaar, R., \& Cabri, J. M. (2012). Gender Differences in the Kinematics and Ball Velocity of Overarm Throwing in Elite Team Handball Players. Journal of Sports Sciences, 32, 345-352. 
Scientific Research Publishing (SCIRP) is one of the largest Open Access journal publishers. It is currently publishing more than 200 open access, online, peer-reviewed journals covering a wide range of academic disciplines. SCIRP serves the worldwide academic communities and contributes to the progress and application of science with its publication.

Other selected journals from SCIRP are listed as below. Submit your manuscript to us via either submit@scirp.org or Online Submission Portal.
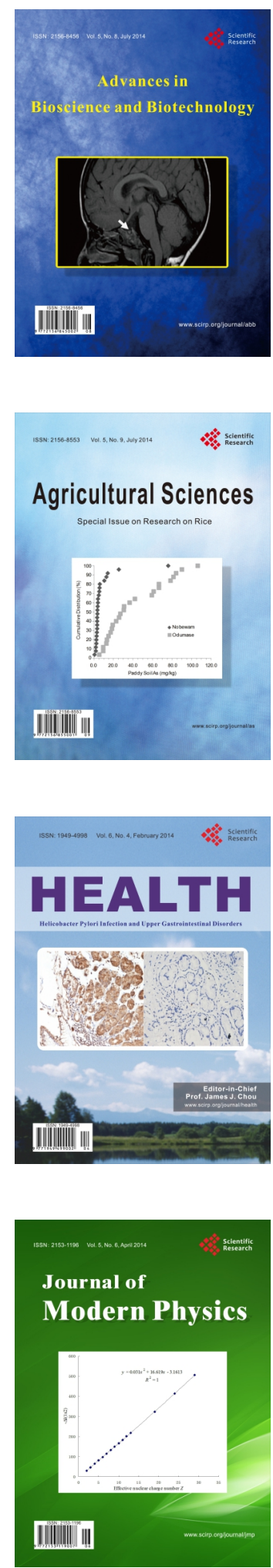
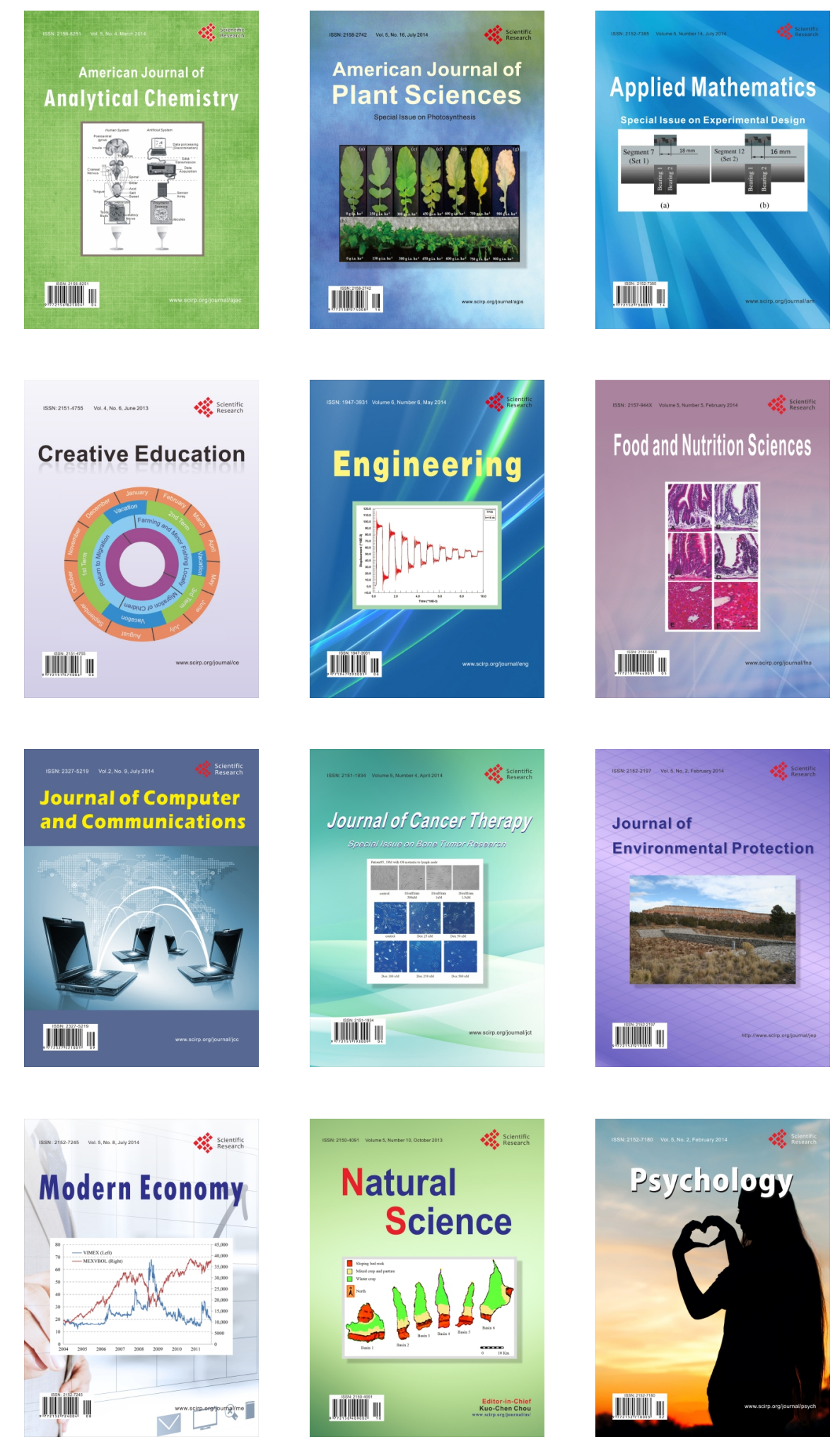